\title{
First description of in situ primate and faunal remains from the Plio-Pleistocene Drimolen Makondo palaeocave infill, Gauteng, South Africa
}

\author{
Douglass S. Rovinsky, Andy I.R. Herries, Colin G. Menter, and Justin W. Adams
}

\begin{abstract}
The Drimolen palaeocave system has been actively excavated since the 1990s and has produced a demographically-diverse record of Paranthropus robustus, early Homo, and a substantial record of early Pleistocene bone tools; all recovered from the Main Quarry, a single fossil bearing deposit within the system. Early surveys identified an isolated solution-tube 55 meters west of the Main Quarry filled with decalcified matrix and fossils (the Drimolen Makondo). Recent excavations into the Makondo have started to address the geology, depositional history, and faunas of the deposits; particularly whether the Makondo represents a distant uneroded part of the Main Quarry infill, or deposits in-filled into a separate entrance within the same system. We present the first description of fossil macromammalian faunas from the Makondo, excavated 2013-2014. A total of 531 specimens were recovered, $268(50.5 \%)$ of which are taxonomically identifiable. The resulting list is diverse given the sample size and includes primate and carnivore taxa frequently recovered at other terminal Pliocene and earlier Pleistocene localities, as well as more rarely encountered species and elements like the first postcranial remains of the hunting hyaenid (Chasmaporthetes ?nitidula) from the Cradle. While some of the Makondo fauna overlaps with taxa recovered from the Main Quarry, there are key differences between the described samples that may reflect differences in the age of the deposits and/or taphonomic processes between these deposits at Drimolen.
\end{abstract}

Douglass S. Rovinsky. Biology Department, Grand Valley State University, Allendale, Michigan 49401, USA rovinsdo@gvsu.edu.

Andy I.R. Herries. The Australian Archaeomagnetism Laboratory, Dept. Archaeology and History, La Trobe University, Melbourne Campus, Bundoora, Victoria 3086, Australia. a.herries@latrobe.edu.au and Centre for Anthropological Research, Humanities Research Village, University of Johannesburg, Auckland Park 2006, South Africa.

Colin G. Menter. Centre for Anthropological Research, Humanities Research Village, University of Johannesburg, Auckland Park 2006, South Africa. menterc@drimolen.org Justin W. Adams. Department of Anatomy and Developmental Biology, Monash University, Clayton, Victoria 3800, Australia. justin.adams@monash.edu.

Rovinsky, Douglass S., Herries, Andy I.R., Menter, Colin G., and Adams, Justin W. 2015. First description of in situ primate and faunal remains from the Plio-Pleistocene Drimolen Makondo palaeocave infill, Gauteng, South Africa. Palaeontologia Electronica 18.2.34A: $1-21$

palaeo-electronica.org/content/2015/1231-drimolen-makondo-fauna 
Keywords: Cercopithecoides; Chasmaporthetes; Dinofelis; Paranthropus robustus; Metridiochoerus; Cradle of Humankind; Drimolen; cave sites

Submission: 27 February 2015. Acceptance: 27 May 2015

\section{INTRODUCTION}

Since the 1990s, excavation at the Drimolen palaeocave system (Cradle of Humankind World Heritage Site, South Africa), located $5.5 \mathrm{~km}$ northeast of the well-described Blauubank Valley hominin localities (e.g., Sterkfontein, Swartkrans, Kromdraai), has produced a rich record of fossil hominins (Paranthropus robustus, early Homo), bone tools, and mammals (Figure 1; Keyser, 2000; Keyser et al., 2000; Backwell and d'Errico, 2008; Moggi-Cecchi et al., 2010). While other fossil-bear- ing portions of the Drimolen palaeocave system have been known for some time, until recently excavations at Drimolen have exclusively focused on the Main Quarry, the portion of the palaeocave system that was heavily mined for speleothem. Faunal correlations with other South African fossil sites has suggested similarity to both Swartkrans Member 1 (1.96-1.80 Ma) and Cooper's D ( 1.6$<1.4 \mathrm{Ma}$ ) assemblages, and these sites have been used to give a broad age estimate of somewhere between $\sim 2.0-\sim 1.4 \mathrm{Ma}$ for the Main Quarry faunas (Keyser et al., 2000; O'Regan and Menter, 2009;

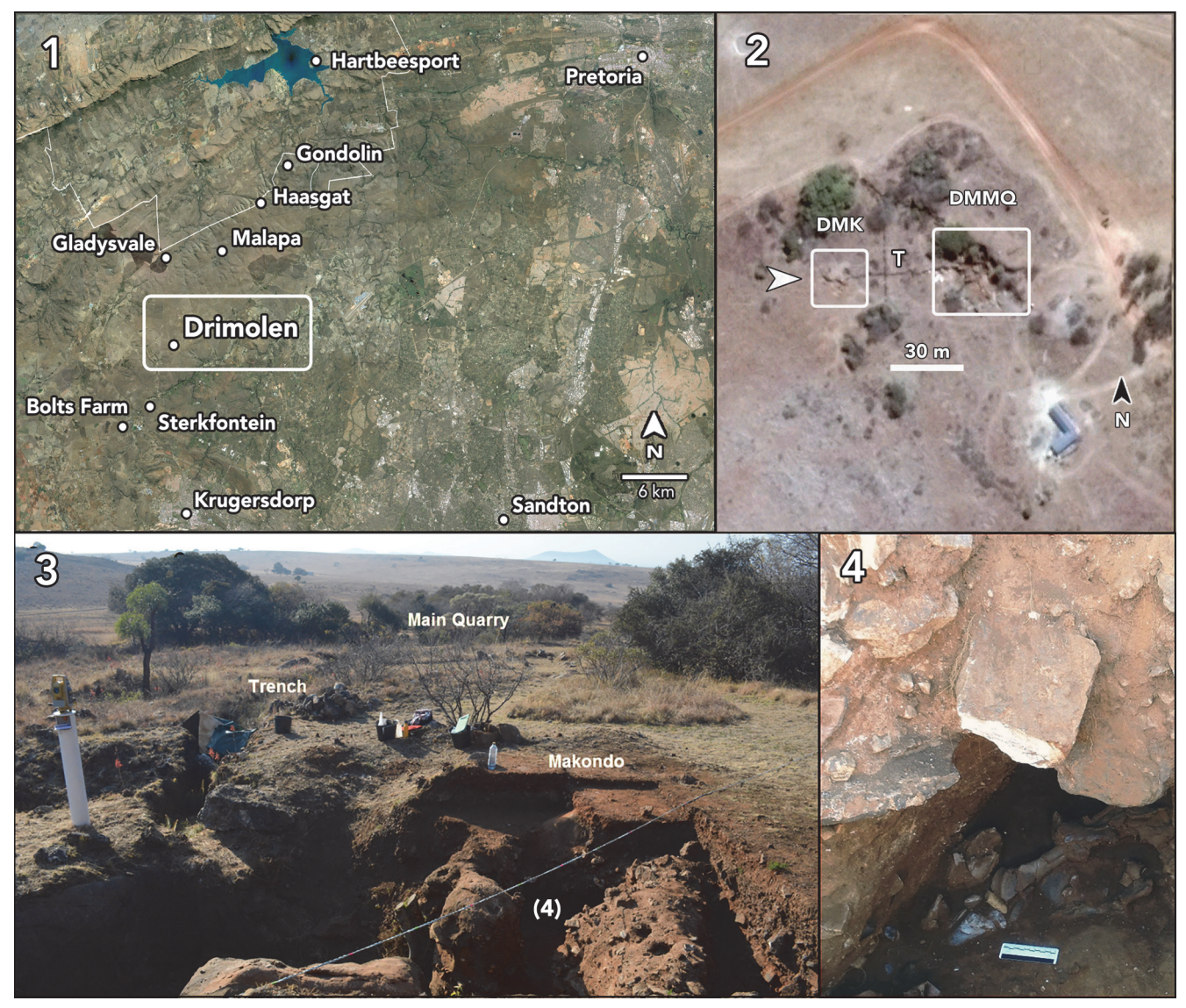

FIGURE 1. 1, Location of Drimolen compared to Pretoria in the NE and Krugersdorp in the SW as well as other fossil sites in the UNESCO Cradle of Humankind World Heritage Area (Google Earth). 2, Google Earth image of the Drimolen hominin site showing the relationship of the Main Quarry (DMMQ) site from which the hominins have been recovered and the new Makondo site (DMK) that is the focus of this paper. T represents the location of Andre Keyser's preliminary excavation trench, the white arrow indicates the view in Figure 1.3. 3, the Makondo excavations in progress in 2014 showing the various Makondo features from which the fossils were recovered and looking east. In Figure 1.3 (4) denotes the location of Figure 1.4. 4, In situ fossils during excavation in 2014, showing the heavy manganese staining and concentration of fossils. 


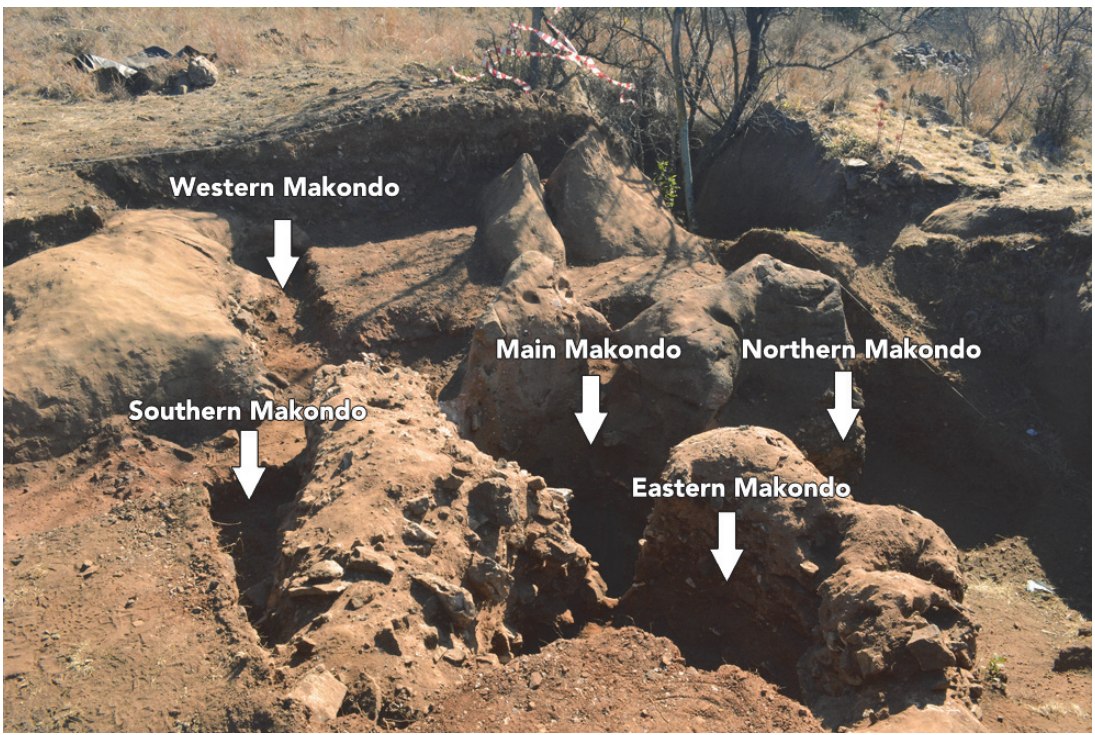

FIGURE 2. The Drimolen Makondo deposit and features at the end of the 2014 excavation season. Fossils were recovered from decalcified deposits adhering to the walls of the Main Makondo in 2013 and mainly from within the northern and eastern portions of the Eastern Makondo in 2014. While the fossils are defined as having come from different makondo features these solution tubes have all been formed within the same depositional unit of the Drimolen Makondo.

de Ruiter et al., 2009; Pickering et al., 2011; Herries and Adams, 2013). The apparent occurrence of Dinofelis aff. piveteaui (O'Regan and Menter, 2009) may suggest that the Drimolen Main Quarry deposit may fall at the younger end of this age range as it is similar to the Dinofelis sp. dental material found at the younger Cooper's $D$ site.

In the early phases of exploration at the site a small makondo (a karst solution tube that formed from dissolution of calcified sediments by tree roots) was identified that contained a dense accumulation of fossil material (Keyser et al., 2000; Figure 1.2). This is but one of a series of fossil-bearing deposits that occurs to the west and higher on the hillside above the Main Quarry and whose ecological and temporal association to the Main Quarry infill has not yet been established. A number of these deposits were identified when Andre Keyser excavated a long trench between the Main Quarry and the Makondo in the 1990s (Keyser et al., 2000). A cross trench excavated later by Colin Menter identified additional fossil bearing palaeokarst (Keyser et al., 2000). In 2014, ground penetrating radar was used to try and establish the extent of the Makondo deposits and other fossil bearing palaeokarst around the Main Quarry. This work, including excavation around the main Makondo, has identified additional solution cavities (Eastern Makondo, Western Makondo, Southern Makondo) that also contain decalcified, fossilifer- ous infillings (Figure 1.3-4). Trending north from this complex of solution cavities is a rift-like solution feature (Northern Makondo) into the dolomitic bedrock that has adhering palaeocave deposits along the western and southern walls that is particularly rich in micromammals.

Although the Drimolen Makondo was known to be fossiliferous since its discovery, the locality was not sampled until July 2013 when excavation into the decalcified wall sediments was undertaken because the decalcified portions of the deposits were in danger of collapsing. During the 2013 excavations, several sets of articulated remains removed from the decalcified portion of the walls of the Makondo were noted as continuous with specimens in the still calcified wall sediments. As such, we are extremely confident that the material removed from the Makondo walls represents the decalcified portions of the original calcified cave fill and not a later infilling of the solution feature. Wellpreserved, heavily manganese-stained faunal materials were recovered from decalcified deposits hanging from the walls of the Main Makondo deposits in 2013. This was followed by excavations in 2014 into the decalcified sediments of the Main, Eastern, Southern, and Western Makondo portions of the complex; although the majority of the identifiable fossil material recovered during 2014 came from the Eastern Makondo. Overall, the vertical separation of the fossils discovered to date covers 
less than a metre and the horizontal separation is just over $2 \mathrm{~m}$. All the material is considered to have been recovered from the same depositional unit, despite recovery from different decalcified solution tubes (Figure 2). As in the Main Makondo, the material excavated often continued in part into the calcified walls of the deposit and was left in situ if not loose. The exception was an articulated primate leg from the Western Makondo that was removed as it was in danger of being damaged by falling rocks from above.

This paper presents the first description of fossil macromammals excavated from the Drimolen Makondo (Main, Eastern, Southern, and Western). These data are used to establish basic information on the taxonomic representation within the deposits and provide an initial interpretation of the taphonomy of the accumulation, as well as to explore the relationship of the Drimolen Makondo faunal assemblage and depositional history to the hominin-bearing Main Quarry deposits.

\section{MATERIALS AND METHODS}

Excavations into the Makondo decalcified sediments in 2013 and 2014 were conducted with a Topcon() GPT7505 reflectorless total station to record stratigraphic information and piece-plot all recovered fossil specimens. All excavation data was also recorded on an iPad@ (Apple, Inc.) using the Tap Forms@ (Tap Zapp Software, Inc.) application on-site.

Despite the natural decalcification of the Makondo infills the faunal material is extremely well-preserved. The specimens are uniformly manganese stained (from dark grey to black) and in some cases have an adhering manganese crust. Some cleaning of diagnostic specimen surfaces (e.g., dentition, articular surfaces) was undertaken using dry and wet brushing, but no attempt was made to prepare or fully clean surfaces that resisted light preparation.

All specimens excavated from the Makondo deposits were directly compared to modern comparative skeletal materials housed at the Evolutionary Studies Institute at the University of the Witwatersrand (Johannesburg, South Africa) and the Ditsong National Museum of Natural History (DNMNH; Department of Vertebrates, Large Mammals Section, Pretoria, South Africa). Scaled photographs and measurements were used for further comparisons to modern skeletal collections housed at the Mammalogy Research Collection, Michigan State University Museum (Lansing, MI, USA). Fur- ther taxonomic comparisons were made to previously published (Keyser et al., 2000; O'Regan and Menter, 2009) and unpublished fossil specimens from the Drimolen Main Quarry and the Makapansgat Limeworks deposits curated at the Evolutionary Studies Institute (University of the Witwatersrand), and the Plio-Pleistocene Section of the DNMNH (e.g., specimens from Sterkfontein Member 4 and 5, Swartkrans Members 1-3, Kromdraai A and B, Gondolin GD 2, and Cooper's A and B).

Linear measurements of specimens reported here were taken with Mitutoyo $500150 \mathrm{~mm}$ calipers (Mitutoyo Corp., Japan) following published guidelines for craniodental (e.g., mesiodistal length [MD] and buccolingual width [BL]; Swindler, 1976; von den Driesch, 1976; Janis, 1988) and postcranial elements (von den Driesch, 1976). All specimens were photographed with a Nikon D5100 SLR camera body fitted with a Nikon AF-S $85 \mathrm{~mm}$ F3.5G ED VR Micro lens (Nikon Corp., Japan).

\section{Anatomical Abbreviations}

Con-Ang, distance from the top of the condyle to the bottom of the angle; Con DV, dorsoventral height of the condyle; Con W, width of the condyle; Cor-Ang, distance from the top of the coronoid process to the bottom of the angle; $\mathrm{DH}$, distal height (dorsoventral); DW, greatest distal width (mediolateral); L, total length; $\mathbf{P H}$, greatest proximal height; PW, greatest proximal width; $\mathbf{S H}$, diaphysis height at midpoint; Sub $\mathbf{m} 1 \mathbf{H}$, height of the mandible from the carnassial notch to the ventral margin of the corpus, perpendicular to the corpus; Sub $\mathbf{m 1} \mathbf{~ W}$, width of the corpus at the position of Sub $\mathrm{m} 1 \mathrm{H}$; SW, diaphysis width at midpoint; TL, greatest total length; Tri L, length of the trigonid from the front of the paraconid to the back of the metaconid; VL, volar surface length (anteroposterior); VW, volar surface width; W, total width.

\section{RESULTS}

A summary of the identifiable specimens recovered to date from the Drimolen Makondo infill (Main, Western, Southern, and Eastern combined) is provided in a summarised faunal listing (Table 1 ). Of the 531 specimens recovered, $65(12.2 \%)$ are identifiable craniodental, $203(38.2 \%)$ are identifiable postcranial, and $263(49.5 \%)$ were indeterminate elements. Of the latter group, the majority of individual specimens $136 \quad(51.7 \%)$ represent unidentifiable diaphyseal fragments, while 44 $(16.7 \%)$ are epiphyseal or metaphyseal fragments. 
TABLE 1. Listing of fauna from the Drimolen Makondo macromammalian assemblage. NISP, number of individual specimens; MNI, minimum number of individuals.

\begin{tabular}{|c|c|c|}
\hline Taxon & NISP & MNI \\
\hline \multicolumn{3}{|l|}{ Order Primates } \\
\hline \multicolumn{3}{|l|}{ Family Cercopithecidae } \\
\hline \multicolumn{3}{|l|}{ Subfamily Colobinae } \\
\hline Cercopithecoides sp. & 2 & 2 \\
\hline Cercopithecidae indet. & 13 & 1 \\
\hline \multicolumn{3}{|l|}{ Order Carnivora } \\
\hline \multicolumn{3}{|l|}{ Family Canidae } \\
\hline Vulpes chama & 14 & 1 \\
\hline \multicolumn{3}{|l|}{ Family Felidae } \\
\hline Dinofelis sp. & 3 & 1 \\
\hline \multicolumn{3}{|l|}{ Family Hyaenidae } \\
\hline Chasmaporthetes ?nitidula & 7 & 1 \\
\hline \multicolumn{3}{|l|}{ Order Artiodactyla } \\
\hline \multicolumn{3}{|l|}{ Family Bovidae } \\
\hline \multicolumn{3}{|l|}{ Tribe Alcelaphini } \\
\hline Alcelaphin indet. & 2 & 1 \\
\hline \multicolumn{3}{|l|}{ Tribe Antilopini } \\
\hline Antilopin indet. & 1 & 1 \\
\hline \multicolumn{3}{|l|}{ Tribe Hippotragini } \\
\hline Hippotragus sp. & 9 & 1 \\
\hline Bovidae indet. & 133 & 1 \\
\hline \multicolumn{3}{|l|}{ Family Suidae } \\
\hline Metridiochoerus sp. & 1 & 1 \\
\hline \multicolumn{3}{|l|}{ Order Perissodactyla } \\
\hline \multicolumn{3}{|l|}{ Family Equidae } \\
\hline cf. Eurygnathohippus cornelianus & 1 & 1 \\
\hline Total & 186 & 12 \\
\hline
\end{tabular}

\section{Systematic Palaeontology}

Order PRIMATES Linnaeus, 1758

Family CERCOPITHECIDAE Gray, 1821

Subfamily COLOBINAE Jerdon, 1867

Tribe COLOBINI Blyth, 1875

Genus CERCOPITHECOIDES Mollet, 1947

Type species. Cercopithecoides williamsi Mollet, 1947

Cercopithecoides sp. (Mollet, 1947)

Figure 3, Table 2

Referred specimens. DNM 1, partial mandible preserving left and right $\mathrm{C}_{-} \mathrm{P}_{4}$; $\mathrm{DNM} 95$, right premaxilla and maxilla preserving $\mathrm{I}^{1} \mathrm{C}$.
Description. DNM 1 is a partial mandible preserving the symphysis, the left corpus, and the right corpus to the ascending ramus (Figure 3.1-2; Table 2). Both the left and right $\mathrm{C}-\mathrm{P}_{4}$ are intact, with the left corpus missing posterior to the $\mathrm{P}_{4}$ and the right corpus preserving the alveolar process for the $M_{1}-M_{3}$. The right ascending ramus preserves the base, gonion, and the condylar process but lacks a prominentia lateralis. The symphysis is well-buttressed posterior to the incisor alveoli by the superior transverse torus. The corpus is distinctly buccolingually wide at the level of the $\mathrm{M}_{3}$ alveolus, tapering sharply and distinctly mediolaterally 'pinched' on the inferior margin. 

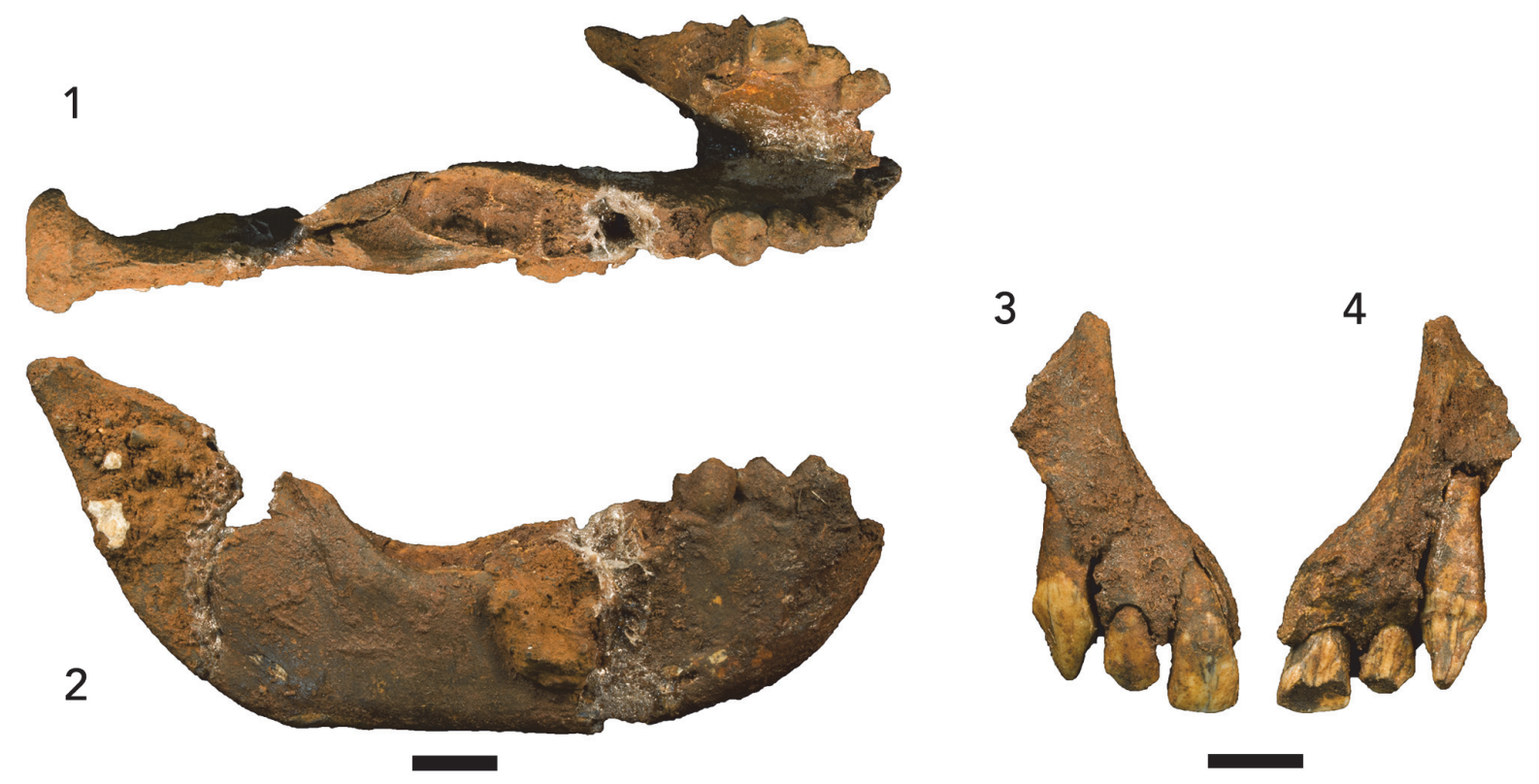

FIGURE 3. Cercopithecoides sp. craniodental specimens from the Drimolen Makondo. 1 and 2, DNM 1, partial mandible; 1, dorsal and 2, right lateral views. 3 and 4, DNM 95, right premaxilla and maxilla; 3, labial and 4, lingual views. Scale bars equal $1 \mathrm{~cm}$.

TABLE 2. Linear measurements (in $\mathrm{mm}$ ) of Cercopithecoides sp. teeth. $\mathrm{LL}=$ labiolingual, $\mathrm{BL}=$ buccolingual, $\mathrm{MD}=$ mesiodistal. Boldface indicates article specimens.

\begin{tabular}{|c|c|c|c|c|c|c|c|c|c|c|c|c|c|}
\hline Specimen & Side & $I^{1} \mathrm{LL}$ & $I^{1}$ MD & $1^{2} \mathrm{LL}$ & $I^{2}$ MD & $\mathrm{C}^{1} \mathrm{LL}$ & $\mathrm{C}^{1} \mathrm{MD}$ & $\mathrm{C}_{1} \mathrm{LL}$ & $\mathrm{C}_{1} \mathrm{MD}$ & $P_{3} B L$ & $P_{3} M D$ & $P_{4} B L$ & $\mathrm{P}_{4} \mathrm{MD}$ \\
\hline DNM 1 & Left & & & & & & & 5.61 & 4.55 & 5.25 & 7.66 & 6.75 & 7.08 \\
\hline DN 861 & Right & & & & & & & & & 5.19 & & 6.85 & 7.47 \\
\hline DN 889 & Right & & & & & & & & & & & 5.49 & 7.57 \\
\hline DNM 95 & Right & 5.54 & 7.66 & 5.24 & 6.34 & 6.79 & 7.99 & & & & & & \\
\hline
\end{tabular}

The small craniofacial fragment DNM 95 is a complete right premaxilla and small maxillary fragment, preserving the bone to the interpremaxillary suture and $1^{1}, 1^{2}$, and canine (Figure 3.3-4; Table 2 ). The transverse maxillo-premaxillary suture is open, and it is likely that the interpremaxillary suture was also similarly unfused. The tip of the canine root is exposed on its lingual surface in the alveolus and is incompletely closed. There is no wear facet on the canine, and only light occlusal wear on the $1^{2}$.

Discussion. The morphology and small size of the canines in both DNM 1 and DNM 95 relative to the adjacent dentition indicates that both specimens are from female individuals. Though roughly similar in size, there is no clear spatial association between the elements and they likely represent two different individuals. The significant manganese crust on the anterior dentition and the lack of postcanine dentition makes establishing age-at- death for the DNM 1 mandible difficult, beyond noting the original presence of an erupted $M_{3}$ suggests minimally an adult individual. While both timing and extent of palatal suture closure in colobines is variable (Chopra, 1957), the incomplete closure of the canine root in DNM 95 may indicate that the specimen was minimally a late $\left(\sim \mathrm{M}_{3}\right.$ eruption) subadult (Havarti, 2000).

The genus Cercopithecoides has been recovered from most of the other South African terminal Pliocene and earlier Pleistocene localities (e.g., Makapansgat Member 3, Sterkfontein Member 4, Swartkrans Members 1 and 2, Haasgat, Kromdraai B, Bolt's Farm; Freedman, 1957; Jablonski and Frost, 2010; Adams, 2012), including the Drimolen Main Quarry (Keyser et al., 2000). Although South African fossil colobines have traditionally been attributed to the extinct species Cercopithecoides williamsi (with noted variability; Freedman, 1957; Delson, 1984), more recent research has argued 
for the occurrence of at least three distinct species across these deposits (McKee et al., 2011; Anderson et al., 2014).

The DNM 1 mandible contrasts with the smaller Cercopithecoides haasgati (McKee et al., 2011) in overall corpus dimensions of both males and females, including the robusticity of the superior transverse torus. DNM 1 also varies from Main Quarry C. williamsi specimens (DN 861, DN 889) in several features: the absence of a prominentia lateralis (positioned near the mesial root of the $\mathrm{M}_{3}$ on DN 861), the lack of the buccolingually wide corpus at the $\mathrm{M}_{3}$ and mediolateral compression of the inferior corpus in both DN 861 and 889 , the more buccolingually narrow and mesiodistally elongate $\mathrm{P}_{4}$ preserved on DN 889, and the greater mesiodistal length of the postcanine toothrow (DN 861). In comparison to similar Cercopithecoides elements, the DNM 1 mandible most closely resembles the Kromdraai B KB 680/686 mandible in possessing a wide and deep symphyseal region, the apparent enlarged postcanine dentition (based on the alveolar process, particularly the buccolingually expanded support for the $\mathrm{M}_{3}$ ), and overall corpus morphology (including the planum alveolare and superior transverse torus). The incisive alveolar and superior torus morphology is also similar to that in the Bolt's Farm female mandible (BF 42b), although we note that the mandibular symphysis of DNM 1 has a steeper slope from alveolus to inferior margin.

The DNM 95 maxilla and premaxilla preserves the lateral margin of the nasal aperture that appears to have been ovoid with a narrow inferior aperture that contrasts the broader nasal aperture shape of $C$. haasgati. The preserved contour of the nasal aperture of the DNM specimen is most consistent with the ovoid aperture shape of the KB 5241 female cranium, although we note that the KB 5241 inferior margin appears misaligned and may be artificially narrow.

Recently, Anderson et al. (2014) have noted the unique craniodental morphology (metric and non-metric) of the Kromdraai $B$ sample relative to other South African fossil colobines historically placed within $C$. williamsi. The KB specimens most closely resemble the extinct colobine Cercopithecoides kimeui, a species currently only established at eastern African localities (Jablonski and Frost, 2010; Anderson et al., 2014), but may represent a novel species (potentially Cercopithecoides coronatus Broom et al., 1950 from the KB 122 neurocranial vault; Freedman and Brain, 1972; Anderson et al., 2014). Until further analysis (and potentially formal separation) of the Kromdraai B sample, we defer attribution of the Drimolen Makondo specimens past the genus level.

Cercopithecidae gen. et sp. indet.

Referred specimens. DNM 10, two articulating left mandibular canine fragments; DNM 53-1 - 53-3, articulating femoral diaphyseal fragments; DNM 265, proximal phalanx; DNM 313-1 - 313-8, long bone diaphyseal fragments (provisional); DNM 492-1, left first metacarpal; DNM 492-2, left second metacarpal; DNM 492-3, left third metacarpal.

Description. A small collection of primate specimens could represent either a papionin or, given the recovery of Cercopithecoides craniodental remains, a large colobine. The DNM 10 left mandibular canine preserves the crown with a distinct wear facet for the maxillary canine. The femoral diaphyseal fragments (DNM 53-1 - 53-3) preserves the linea aspera and parts of both supracondylar ridges just proximal to the distal metaphyseal region. Specimens DNM 53-1 and 532 have small diameter $(<2 \mathrm{~mm})$ pits that may reflect perimortem carnivore damage. The DNM 265 complete proximal phalanx preserves a curved diaphysis with strong flexor tendon sheaths extending nearly the entire length of the ventral diaphysis. Specimens DNM 313-1 - 313-8 are a series of indeterminate long bone diaphyseal fragments that match the DNM 53 specimens in size, cortical thickness, and curvature and may represent parts of the same and/or antimeric femur. These specimens were found in close association with the DNM 53 specimens, but are not independently diagnostic. We consider their attribution as cercopithecid elements as provisional, but probable given their morphology and spatial context.

The last group, DNM 492-1 - 492-3, represents the partial left manus of an indeterminate cercopithecid in semi-articulation. Specimen DNM 492-1 is a complete first metacarpal. DNM 492-2 is comprised of a proximal articular surface with a small amount of diaphysis present and a distal articular surface. These two fragments do not directly articulate, as there is missing diaphysis; however, both pieces are consistent with being from a left metacarpal II and are most likely from the same element. Metacarpal III (DNM 492-3) is a complete element broken in two portions, with a proximal articular surface and shaft complete to the distal metaphysis, and the separate distal articular surface. The partial manus is smaller than that of extant Papio ursinus and could represent either a papionin or large colobine (e.g., Cercopithecoides). 

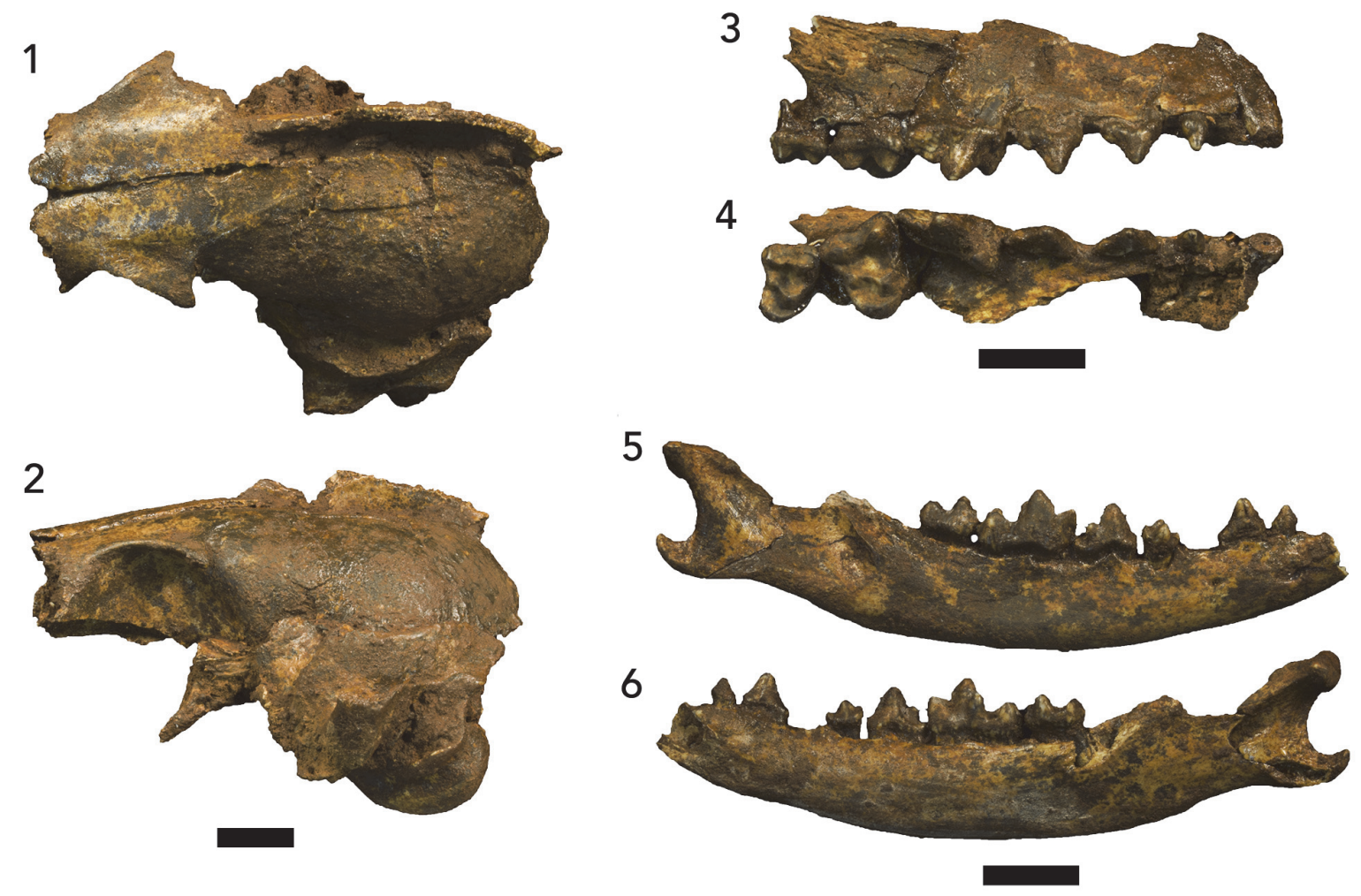

FIGURE 4. Vulpes chama craniodental specimens from the Drimolen Makondo. 1 and 2, DNM 471-1, partial cranium; 1, dorsal and 2, left lateral views. 3 and 4, DNM 471-2, right maxilla; 3, buccal and 4, occlusal views. 5 and 6 , DNM 471-3, right mandible; 5, buccal and 6, lingual views. Scale bars equal $1 \mathrm{~cm}$.

Order CARNIVORA Bowditch, 1821 Family CANIDAE Batsch, 1788

Tribe VULPINI Hempritch and Ehrenberg, 1832 Genus VULPES Frisch, 1775

Type species. Vulpes vulpes Linnaeus, 1758 Vulpes chama (Smith, 1833) Figure 4, Table 3

Referred specimens. DNM 471-1, partial cranium; DNM 471-2, right maxilla preserving C-M2; DNM 471-3, right mandible preserving $\mathrm{P}_{1}-\mathrm{M}_{2}$; DNM 4714, left mandible preserving $\mathrm{P}_{4}-\mathrm{M}_{1}$; DNM 471-5, atlas; DNM 471-6, axis; DNM 471-7, right distal scapula; DNM 471-14, left $p_{3}$.

Description. A total of seven craniodental and postcranial specimens have been recovered from the Drimolen Makondo infill, representing the associated remains of a single subadult individual (Figure 4; Table 3). The retention of the $p_{3}$ and the alveolus for an erupted $\mathrm{M}_{3}$ in the DNM 471-3 specimen suggests the individual was $\sim 20-27$ weeks of age (based on extant Vulpes vulpes Linnaeus, 1758 dental eruption schedule; Linhart, 1968).

The partial cranium (DNM 471-1; Figure 4.12 ) has been crushed both mediolaterally and dorsoventrally, such that the left vault elements (frontal, parietal, interparietal, and squamous temporal) remain in articulation, but the right vault elements are distorted and displaced. Despite damage to the basicranium, the ventral surface of the cranium preserves the left auditory bulla and parts (glenoid fossae and zygomatic processes) of both petrous temporals. Additional basicranial elements may be present within the consolidated sediments within the endocranium. Neither the occipital or rostral cranial portions (e.g., ethmoid, nasals, premaxillae) are preserved. The associated right maxilla (DNM 471-2; Figure 4.3-4) preserves the alveolar process supporting the $\mathrm{C}-\mathrm{M}^{2}$. While the specimen preserves a strong fossa immediately dorsal to $\mathrm{P}^{2 /}$ $\mathrm{P}^{3}$, no part of the infraorbital foramen, and little of the horizontal process, is preserved.

The right mandible (DNM 471-3; Figure 4.5-6) preserves a nearly complete corpus and ascending 


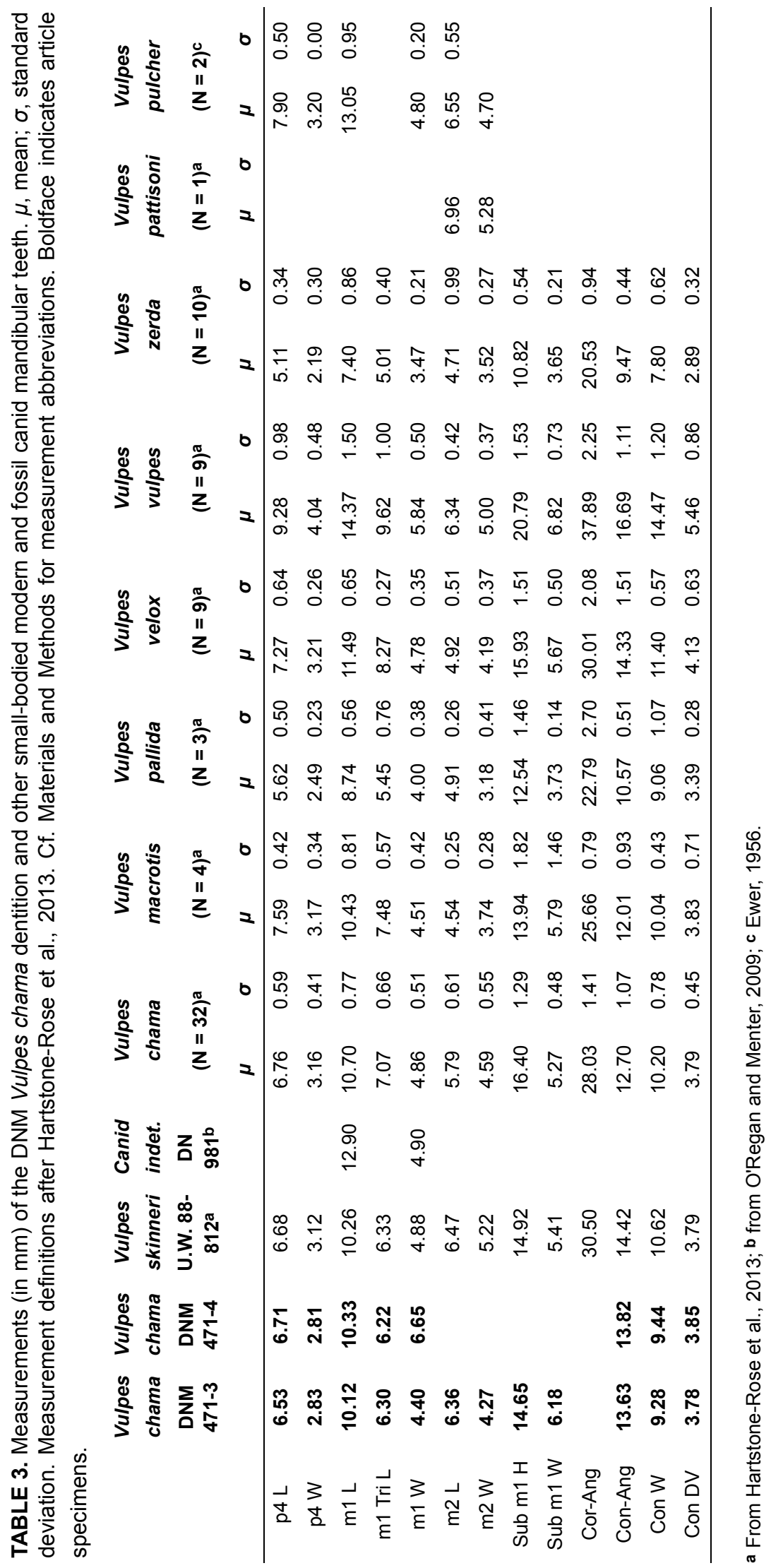


ramus, including gonion and the condylar process but lacking the coronoid process. The alveolar process is complete from the canine through the molar row (indicating $M_{3}$ had erupted), but only the $P_{1}-$ $\mathrm{M}_{2}$ are preserved. There is a distinct diastema between $P_{2}$ and $p_{3}$ to accommodate the $P_{3}$. The corpus possesses two inferior alveolar foramina: one inferior to the $\mathrm{P}_{1}$ mesial root, the other inferior to the $P_{2}$ distal root. The left mandible (DNM 471-4) only preserves the posterior corpus from the alveolus for the $p_{3} / P_{4}$ to the ascending ramus, including the complete $\mathrm{P}_{4}$ and $\mathrm{M}_{1}$, gonion, the condylar process, and most of the coronoid process. The cortex of the medial aspect of the corpus is crushed. An associated isolated left $p_{3}$ (DNM 471-14) is morphologically consistent with the right $p_{3}$ preserved on the DNM 471-3 specimen.

Discussion. Several extant and extinct species of Vulpes (Vulpes pulcher Broom, 1937; Vulpes pattisoni Broom, 1948; and Vulpes skinneri HartstoneRose et al., 2013) have previously been documented from South African Plio-Pleistocene karstic deposits; of these, the preserved cranial and dental morphology of the DNM 471 specimens is only consistent with Vulpes chama. The Makondo individual preserves smaller dentition than those remains attributed to both $V$. pulcher and $V$. pattisoni (Table 3; see Ewer, 1956; Hendey, 1974; Hartstone-Rose et al., 2013), and differs from $V$. skinneri in possessing a strong distal accessory cusp of the DNM 471-3 and 471-4 fourth premolars (the absence of which is an autapomorphy of $V$. skinneri; Hartstone-Rose et al., 2013). While metrically DNM 471 falls just outside the lower range for previously measured adult $V$. chama specimens (Hartstone-Rose et al. 2013), the non-dental metric differences are not unexpected for a subadult individual. Both metric and morphological features of the Makondo $V$. chama specimens are consistent with the previously recovered $V$. chama $\mathrm{M}^{1}$ (DN 1067) described from the Drimolen Main Quarry, including the more rounded edge of the buccal cingulum (O'Regan and Menter, 2009).

Family FELIDAE Batsch, 1788

Genus DINOFELIS Zdansky, 1924

Type species. Dinofelis abeli Zdansky, 1924.

Dinofelis sp.

Figure 5, Table 4

Referred material. DNM 2, left second metatarsal; DNM 54-1, left distal partial calcaneus; DNM 54-2, left proximal partial calcaneus.
Description. Only a single left metatarsal II (DNM 2) and a poorly-preserved left calcaneus in two pieces (DNM 54-1, 54-2) from the Makondo infill are identifiable as Dinofelis. While the metatarsal and calcaneus could represent elements from the same individual there is no direct association between the remains (the calcaneus was found $\sim 50 \mathrm{~cm}$ above the metatarsal).

DNM 2 is a complete, well-preserved left second metatarsal that is only missing small portions of the diaphyseal cortex at midshaft (Figure 5.1-6). The overall length of DNM 2 is intermediate between modern Panthera pardus and Panthera leo (Lewis, 1995; Table 4), and lacks the proximodistal elongation of the diaphysis expressed in Acinonyx jubatus. In comparison to the Dinofelis aff. piveteaui DN 12 second metatarsal described from the Drimolen Main Quarry (O'Regan and Menter, 2009), DNM 2 is larger and more elongate and gracile in appearance (Table 4). Proximally, the metatarsal III articular surface of DNM 2 is continuous from the dorsal to plantar surface, but is interrupted by a distinct concavity in DN 12. In addition, a distinct fossa plantar to the metatarsal III facet on the DN 12 specimen is absent in DNM 2 (O'Regan and Menter, 2009). The plantar aspect of the proximal articular surface of DNM 2 is flat and broadly supported along the plantar metaphysis, contrasting the plantar articular aspect of DN 12 that is both concave and supported by a mediolaterally 'pinched' ridge on the plantar metaphysis. On the medial aspect, DNM 2 preserves a continuous ridge on the metaphysis and proximal diaphysis extending from the proximal articular surface, whereas in DN 12 there is a distinct, isolated tuberosity. Distally, the epicondylar region appears less robust than in DN 12, while simultaneously the articular surface is more heavily developed (Table 4).

The left calcaneus, DNM 54-1 and DNM 54-2, is broken obliquely at the approximate midpoint of the element (Figure 5.7). As both element components are partially decalcified, most of the fine features were obliterated and only gross measurements and observations were possible. The distal portion (DNM 54-1) preserves the articular surfaces for both the astragalus and cuboid, but lacks the sustentaculum tali. The proximal portion (DNM 54-2) preserves the body and a robust tuberosity. The specimen is visibly larger than both the DN 2149a and DN 2092 Dinofelis aff. piveteaui specimens from the Drimolen Main Quarry (unmeasured because of damage), but smaller than that of Homotherium sp. and extant $P$. leo 

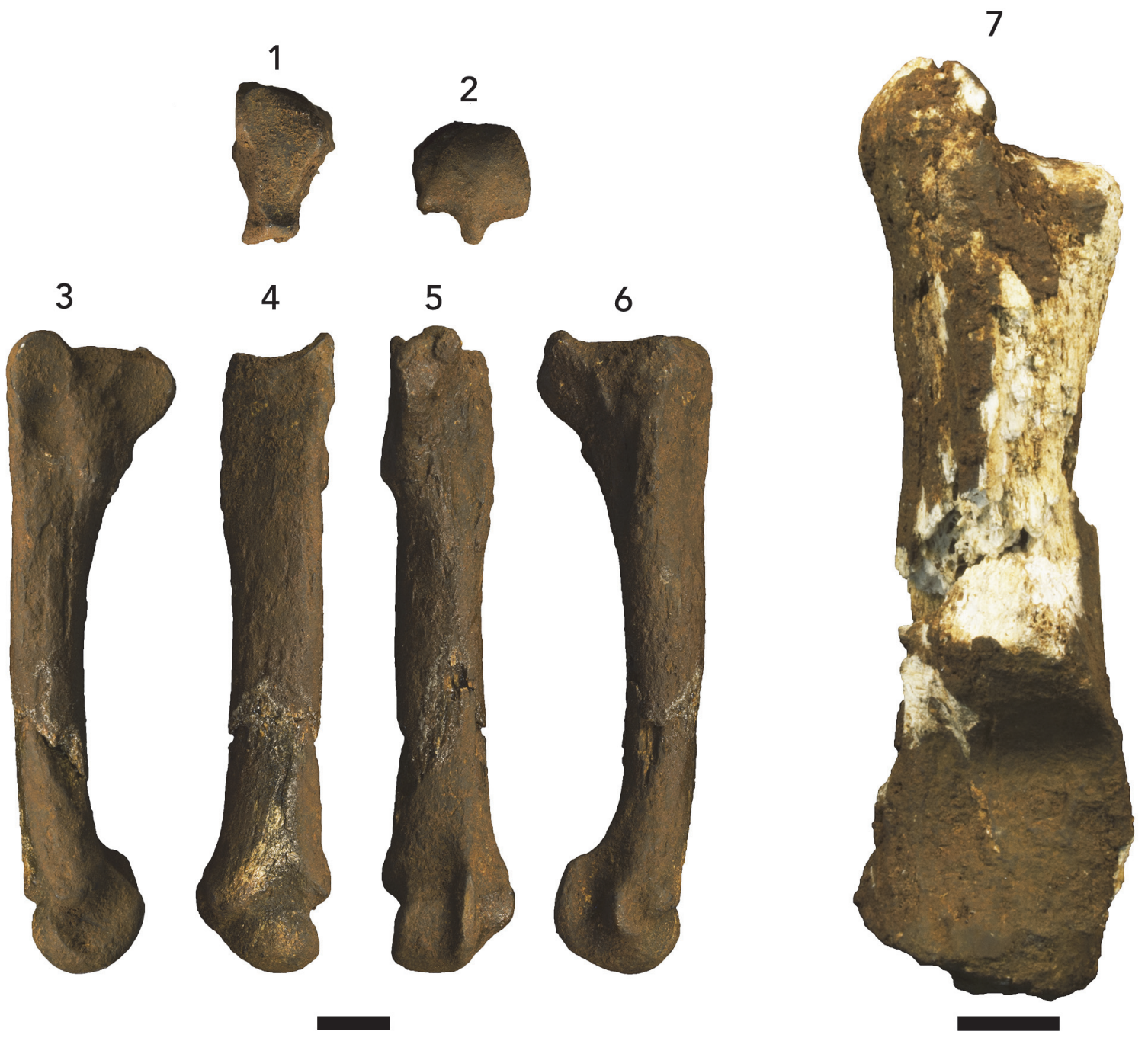

FIGURE 5. Dinofelis sp. postcranial specimens from the Drimolen Makondo. 1-6, DNM 2, left second metatarsal; 1 , proximal and 2, distal articular surfaces, 3, medial, 4, dorsal, 5, ventral, and 6, lateral views. 7, DNM 54-1 and 54-2, left calcaneus in articulation; anterior view. Scale bars equal $1 \mathrm{~cm}$.

(Lewis, 1995). Indeed, DNM 54 is larger than all published Dinofelis calcanei thus far described (Werdelin and Lewis, 2001; O'Regan and Menter, 2009).

Discussion. Although both DNM 2 and DNM 54-1/ 54-2 are both metrically and morphologically consistent with Dinofelis to the exclusion of other felid genera, the poor preservation of the calcaneous and paucity of specifically attributed second metatarsals prevents a more specific attribution of these specimens. We note, however, that the metric and morphological differences of the Makondo infill specimens to the Main Quarry Dinofelis aff. piveteaui remains may reflect either the sampling of a different Dinofelis species, significant postcranial population variability or sexual dimorphism, and/or differences in the depositional timing of the remains.

Family HYAENIDAE Gray, 1821

Genus CHASMAPORTHETES Hay, 1921

Type species. Chasmaporthetes ossifragus Hay, 1921.

\section{Chasmaporthetes ?nitidula (Ewer, 1955)}

Figure 6, Table 5

Referred material. DNM 3-1 and DNM 3-2, two pedal middle phalanges; DNM 3-3, pedal proximal phalanx; DNM 3-4 left partial metatarsal IV; DNM 
TABLE 4. Measurements (in $\mathrm{mm}$ ) of the Drimolen Makondo Dinofelis sp. and comparative metrics of Felidae distal limb elements. Cf. Materials and Methods for measurement abbreviations. Boldface indicates article specimens.

\begin{tabular}{|c|c|c|c|c|c|c|c|c|c|c|}
\hline Specimen & Taxon & Side & Element & TL & PW & $\mathbf{P H}$ & sw & SH & DW & DH \\
\hline DNM 2 & Dinofelis sp. & Left & MT II & 83.2 & 14.2 & 23.1 & 12.0 & 10.6 & 18.0 & 17.4 \\
\hline DN 12 & Dinofelis aff. piveteaui & Left & MT II & 76.7 & 12.7 & & 11.2 & 11.6 & 16.6 & 15.7 \\
\hline KB 5339 A & Megantereon cultridens & Left & MT II & 71.5 & 11.2 & 19.6 & 8.9 & 9.3 & 14.2 & 14.4 \\
\hline KB 5339 B & Megantereon cultridens & Left & MT V & 69.8 & 14.4 & 14.6 & 7.8 & 8.1 & 13.1 & \\
\hline KB 5539 C & Megantereon cultridens & Left & MT IV & 80.1 & 15.9 & 18.5 & 10.9 & 10.7 & 14.5 & 13.8 \\
\hline SK 1848 & Dinofelis barlowi & Right & MT IV & & 15.1 & 17.6 & 10.2 & 10.6 & & \\
\hline DN 2092 & Dinofelis aff. piveteaui & Left & Calcaneus & 75.5 & & & & & & \\
\hline DN 2149c & Dinofelis aff. piveteaui & Right & Calcaneus & 84.0 & & & & & & \\
\hline DNM 54 & Dinofelis sp. & Left & Calcaneus & 90.8 & & & & & & \\
\hline UCMP $88783^{a}$ & Dinofelis barlowi & & Calcaneus & 78.0 & & & & & & \\
\hline UCMP $88784^{a}$ & Dinofelis barlowi & & Calcaneus & 81.9 & & & & & & \\
\hline KNM-ER $722 Q^{a}$ & Dinofelis aff. piveteaui & & Calcaneus & 71.0 & & & & & & \\
\hline (BPI) M 16201a & Dinofelis darti & & Calcaneus & 84.9 & & & & & & \\
\hline KNM-LT 23696a & Dinofelis sp. & & Calcaneus & 83.4 & & & & & & \\
\hline KNM-LT 23932a & Dinofelis sp. & & Calcaneus & 81.3 & & & & & & \\
\hline Extant $(\mathrm{N}=20)^{\mathrm{b}}$ & Panthera leo & & Calcaneus & 103.2 & & & & & & \\
\hline Extant $(N=14)^{b}$ & Panthera pardus & & Calcaneus & 64.3 & & & & & & \\
\hline
\end{tabular}

a From Werdelin and Lewis, 2001, b from Lewis, 1995.

3-5, pedal proximal phalanx; DNM 3-6 and DNM 37 , two pedal terminal phalanges.

Description. DNM 3-4 is a fourth metatarsal preserving the proximal articular surface and a small portion of the diaphysis (Figure 6.1-5). While the articular surface is robust, the proximal end is distinctly mediolaterally compressed relative to extant hyaenids (e.g., Crocuta and Hyaena; Table 5) but follow the proportions and morphology of the single previously described Chasmaporthetes ossifragus third metatarsal (UF 27372; Berta, 1981; Table 5). The medial and lateral aspects preserve the paired (dorsal, triangular; plantar, rectangular) articular facets for the third and fifth metatarsals, respectively. In slight contrast to the UF 27372 specimen, the lateral dorsal articular facet is more robust and extends further towards the plantar surface on DNM 3-4. This extension nearly converges with the plantar facet to close off the shallow concavity that receives the base of the fifth metatarsal.

The proximal phalanges (DNM 3-3 and DNM 3-5) conform to previously described $C$. ossifragus and $C$. gangsriensis phalanges to the exclusion of other hyaenid genera (TRO 1671 and UF 27377; Berta, 1981; IVPP V18567.2; Tseng et al., 2013; Turner, 1993; Figure 6.6-8; Table 5) in exhibiting dorsoventrally deep articular surfaces that are notched on the plantar surface, providing robust insertion platforms for the interosseous muscles on either side of the groove for the flexor digitorum profundus tendon. In dorsal view, the body is strongly waisted near the proximal end, contributing to a distinct mediolateral expansion of the diaphysis near the distal articular surface. In lateral view the body has a slight dorsal arch. There are extensive, laterally-positioned rugosities on the plantar surface that contact the distal articular surface for the flexor sheaths. The distal articular surface is broad, with a shallow dorsoplantar groove forming a trochlea for the middle phalanx.

DNM 3-1 is a partial middle phalanx (proximal articular surface with almost no diaphysis), and DNM 3-2 is a complete middle phalanx (Table 5; Figure 6.9-11). The proximal articular surfaces of both specimens are mediolaterally wide with a median ridge separating the articular surface into medial and lateral concavities. On the ventral surface, the proximal end preserves a robust subtriangular groove for the tendon of the flexor digitorum superficialis. The diaphysis of DNM 3-2 appears mediolaterally waisted from the relatively large size of the proximal and distal articular surfaces, and in 
TABLE 5. Measurements (in $\mathrm{mm}$ ) of the Drimolen Makondo Chasmaporthetes ?nitidula and comparative Hyaenidae distal limb elements. Cf. Materials and Methods for measurement abbreviations. Boldface indicates article specimens.

\begin{tabular}{|c|c|c|c|c|c|c|c|c|c|c|c|}
\hline Specimen & Taxon & Element & TL & PW & PH & sw & SH & DW & DH & VL & VW \\
\hline DNM 3-4 & $\begin{array}{c}\text { Chasmaporthetes } \\
\text { ?nitidula }\end{array}$ & Fourth Metatarsal & & 9.8 & 19.5 & & & & & & \\
\hline Extanta & Crocuta crocuta $(\mathrm{N}=2)$ & Fourth Metatarsal & 88.9 & 9.9 & 15.4 & 9.0 & 8.3 & 10.8 & & & \\
\hline Extanta & Parahyaena brunnea $(\mathrm{N}=1)$ & Fourth Metatarsal & 84.7 & 8.8 & 14.0 & 9.0 & 8.3 & & & & \\
\hline Extanta & Hyaena hyaena $(\mathrm{N}=1)$ & Fourth Metatarsal & 88.4 & 8.3 & 14.2 & 6.2 & 6.3 & 8.7 & & & \\
\hline $\begin{array}{c}\text { IVPP } \\
\text { V18567.1b }\end{array}$ & $\begin{array}{c}\text { Chasmaporthetes } \\
\text { gangriensis }\end{array}$ & Second Metatarsal & $>80.0$ & & & 9.5 & & 13.0 & & & \\
\hline DNM 3-3 & $\begin{array}{c}\text { Chasmaporthetes } \\
\text { ?nitidula }\end{array}$ & Proximal Phalanx & 35.3 & 13.9 & 12.0 & 7.7 & 7.3 & 11.4 & 8.0 & & \\
\hline DNM 3-5 & $\begin{array}{c}\text { Chasmaporthetes } \\
\text { ?nitidula }\end{array}$ & Proximal Phalanx & 35.4 & 13.0 & 11.2 & 7.2 & 6.6 & 10.4 & 8.0 & & \\
\hline TRO 1671a & $\begin{array}{c}\text { Chasmaporthetes } \\
\text { ossifragus }\end{array}$ & Proximal Phalanx & 37.6 & 17.1 & 18.0 & 12.5 & 9.5 & 14.6 & & & \\
\hline UF $27377^{a}$ & $\begin{array}{c}\text { Chasmaporthetes } \\
\text { ossifragus }\end{array}$ & Proximal Phalanx & 38.6 & 12.4 & 13.4 & 7.0 & 8.5 & 11.3 & & & \\
\hline $\begin{array}{c}\text { IVPP } \\
\text { V18567.2 }\end{array}$ & $\begin{array}{c}\text { Chasmaporthetes } \\
\text { gangriensis }\end{array}$ & Proximal Phalanx & 34.4 & 12.6 & & 7.4 & & 10.8 & & & \\
\hline DN 2033c & Hyaenidae sp. & Proximal Phalanx & & & & & & 11.7 & 8.5 & & \\
\hline DN $562^{c}$ & Hyaenidae sp. & Proximal Phalanx & 29.3 & 11.4 & 9.8 & 7.6 & 6.7 & 9.4 & 6.4 & & \\
\hline SKX 28181 & Hyaenidae sp. & Proximal Phalanx & 29.7 & 13.3 & 10.9 & 8.6 & 7.3 & 10.9 & 7.3 & & \\
\hline SKX 29031d & Hyaenidae sp. & Proximal Phalanx & 29.9 & 13.4 & 12.0 & 9.1 & 8.2 & 11.5 & 8.3 & & \\
\hline SKX $27170^{d}$ & Hyaenidae sp. & Proximal Phalanx & 29.9 & 13.5 & 12.0 & 9.0 & 8.2 & 11.4 & 8.3 & & \\
\hline Extanta & Crocuta crocuta $(\mathrm{N}=3)$ & Proximal Phalanx & 27.4 & 9.8 & 9.8 & 6.2 & 6.5 & 9.1 & & & \\
\hline Extanta & Parahyaena brunnea $(\mathrm{N}=1)$ & Proximal Phalanx & 25.2 & 8.7 & 8.7 & 4.4 & 5.7 & 7.7 & & & \\
\hline Extanta & Hyaena hyaena $(\mathrm{N}=1)$ & Proximal Phalanx & 24.7 & 9.2 & 7.7 & 5.6 & 6.3 & 7.9 & & & \\
\hline DNM 3-1 & $\begin{array}{c}\text { Chasmaporthetes } \\
\text { ?nitidula }\end{array}$ & $\begin{array}{l}\text { Intermediate } \\
\text { Phalanx }\end{array}$ & & 11.0 & 8.2 & & & & & & \\
\hline DNM 3-2 & $\begin{array}{c}\text { Chasmaporthetes } \\
\text { ?nitidula }\end{array}$ & $\begin{array}{l}\text { Intermediate } \\
\text { Phalanx }\end{array}$ & 22.4 & 11.9 & 9.0 & 7.5 & 5.3 & 11.6 & 7.6 & & \\
\hline $\begin{array}{c}\text { IVPP } \\
\text { V18567.3b }\end{array}$ & $\begin{array}{c}\text { Chasmaporthetes } \\
\text { gangriensis }\end{array}$ & $\begin{array}{l}\text { Intermediate } \\
\text { Phalanx }\end{array}$ & 24.8 & 11.3 & & 8.1 & & 11.9 & & & \\
\hline SKX 36942d & Parahyaena brunnea & $\begin{array}{l}\text { Intermediate } \\
\text { Phalanx }\end{array}$ & 28.3 & 10.7 & 9.8 & 7.4 & 6.1 & & 7.1 & & \\
\hline DNM 3-6 & $\begin{array}{c}\text { Chasmaporthetes } \\
\text { ?nitidula }\end{array}$ & Distal Phalanx & 19.2 & 8.7 & 13.4 & & & 5.3 & & 10.7 & 7.3 \\
\hline DNM 3-7 & $\begin{array}{c}\text { Chasmaporthetes } \\
\text { ?nitidula }\end{array}$ & Distal Phalanx & 20.7 & 10.3 & 14.5 & & & 5.9 & & 10.8 & 7.8 \\
\hline
\end{tabular}




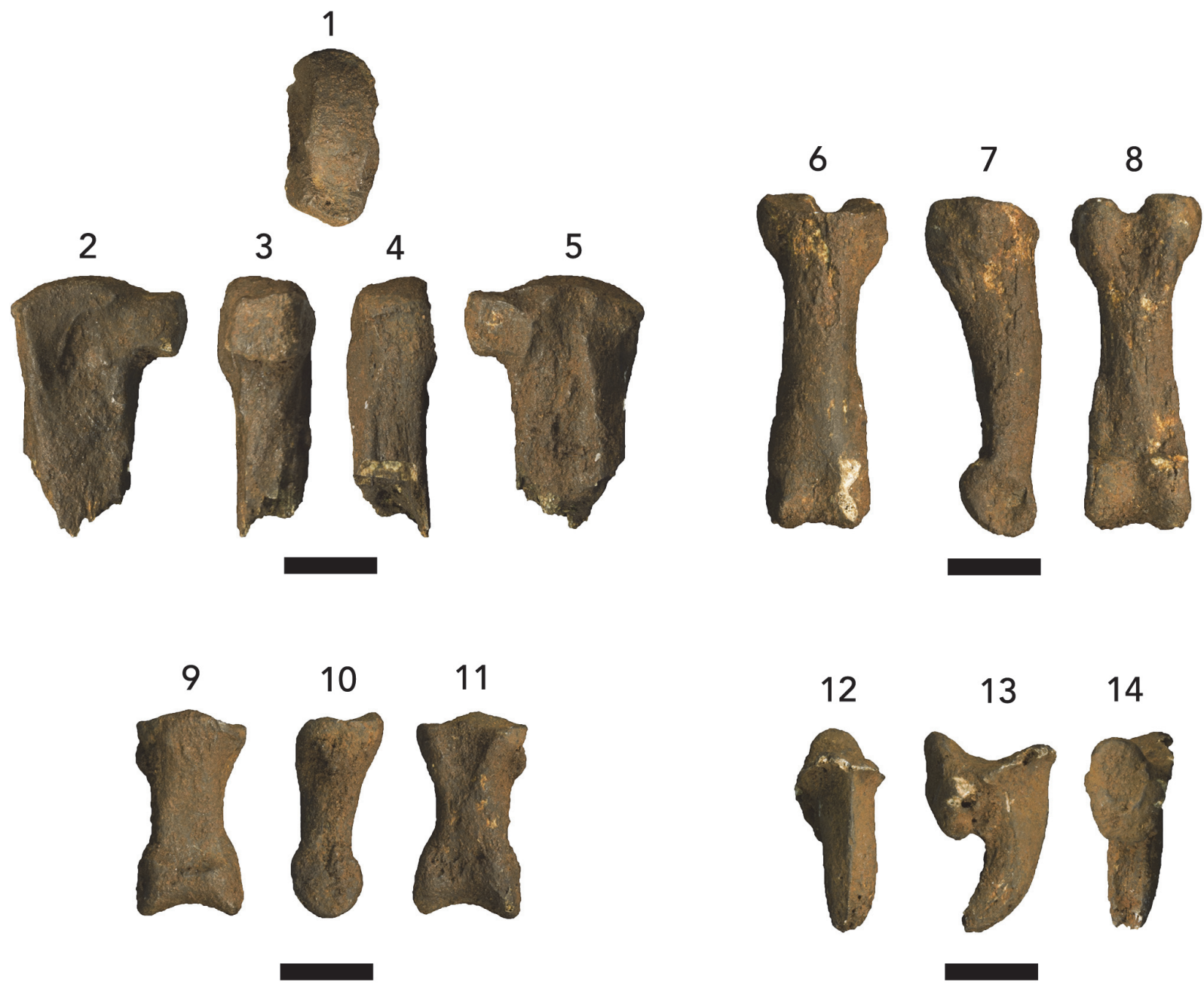

FIGURE 6. Chasmaporthetes ?nitidula postcranial specimens from the Drimolen Makondo. 1-5, DNM 3-4, partial left fourth metatarsal; 1, proximal articular surface, 2, lateral, 3, ventral, 4, dorsal, and 5, medial views. 6-8, DNM 3-3, pedal proximal phalanx; 6, dorsal, 7, lateral, and 8, ventral views. 9-11, DNM 3-2, pedal middle phalanx; 9, dorsal, 10, lateral, and 11, ventral views. 12-14, DNM 3-6, pedal terminal phalanx; 12, dorsal, 13, lateral, and 14, ventral views. Scale bars equal $1 \mathrm{~cm}$.

lateral view the distal body of the phalanx is dorsoplantarly compressed.

The two terminal phalanges (DNM 3-6 and DNM 3-7) have well-developed dorsal extensor processes, but the ungual crest is either poorly preserved on these specimens or was weakly developed (Table 5; Figure 6.12-14). In plantar aspect, there is a robust tubercle for the insertion of the flexor digitorum profundus that extends distally past the ungual crest, resulting in a plantar surface longer than it is wide. The ungual process itself is strongly keeled on the dorsal aspect of DNM 3-6; DNM 3-7 is less well-preserved and this ridging is not present. The keel of the ungual process runs parallel to the long axis of the element from base to tip.

Discussion. The associated DNM 3 specimens represent a partial left pes of a hyaenid that is both metrically and morphologically distinct from both Crocuta and Parahyaena. The metatarsal and phalanges conform to previously described morphology of Chasmaporthetes elements, but are more gracile than the more robust North American taxon (Berta, 1981; Tseng et al., 2013). At present, the Drimolen Makondo specimens have not been directly compared to postcranial elements associated with craniodental remains assigned to Percrocuta (Adcrocuta) australis (L 13033; Hendey, 1974; 1978), reassigned to Chasmaporthetes australis 
(Werdelin and Solounias, 1990), that include a third and fifth metatarsal and seven phalanges (of undescribed position; neither photographs nor measurements of these specimens have been published). At present, the known biogeography of Chasmaporthetes in South Africa during the terminal Pliocene and early Pleistocene would suggest these remains most likely represent Chasmaporthetes nitidula; it is the only currently recognised species in the genus documented in the Cradle of Humankind karstic deposits, and two craniodental specimens are known from the Drimolen Main Quarry (O'Regan and Menter, 2009). At a minimum, these specimens represent one of only two sets of Chasmaporthetes postcrania in Africa, the first attributed postcrania for the genus known from a Cradle locality, and potentially the first $C$. nitidula postcrania in the record.

Order ARTIODACTYLA Owen, 1848

Family BOVIDAE Gray, 1821

Tribe ALCELAPHINI de Rochebrune, 1883

Alcelaphini gen. et $\mathrm{sp}$. indet.

Referred material. DNM 444-1, maxillary enamel fragment; DNM 444-2, two articulating maxillary enamel fragments.

Description. DNM 444-1 and 444-2 are partial maxillary ectoloph enamel fragments. Unfortunately, the degree of preservation does not allow their side or position within the toothrow to be established. The overall size of the ectoloph fragments is consistent with a large Class III bovid (Brain, 1974), morphology of the ectoloph (style and rib) and hypsodonty is consistent with a large alcelaphin.

Discussion. Even as fragmentary remains, these ectoloph portions and the large size of the teeth would exclude all but either an extremely large Connochaetes or (most likely) Megalotragus; however, we defer generic classification. Specimens attributable to both alcelaphin genera have been previously described from the Drimolen Main Quarry (Keyser et al., 2000). We also note that the remains of a larger, skeletally immature Class III bovid (DNM 276-310, 316-431) were recovered during excavation and may represent parts of fragmentary partial skeleton of a single individual.

Tribe ANTILOPINI Gray, 1821

Antilopini gen. et $\mathrm{sp}$. indet.

Referred material. DNM 135, partial right $\mathrm{M}_{1}$ or $\mathrm{M}_{2}$.

Description. DNM 135 is a partial right first or second lower molar. The tooth preserves a heavily worn crown and a partial root.
Discussion. The size of the specimen is consistent with a Class II bovid (Brain, 1974) and the preserved morphology (flat lingual enamel surface, rounded buccal lophids) is consistent with an antilopin. Both Gazella and Antidorcas have been previously described from the Drimolen Main Quarry deposits (Keyser et al., 2000).

Tribe HIPPOTRAGINI Sundevall, 1845

Genus HIPPOTRAGUS Sundevall, 1845

Type species. Hippotragus equinus Geoffroy Saint-Hilaire, 1803.

\section{Hippotragus sp. Figure 7}

Referred material. DNM 143-1, left partial horn core; DNM 143-2 -143-9, small horn core fragments.

Description. DNM 143 is a left horn core of at least a Class III bovid (Brain, 1974), represented by a single large portion (DNM 143-1) and eight small non-articulating fragments likely from a single element (Figure 7.1-2). The larger section preserves the core at the pedicle and a very small portion of the frontal bone external cortex rostral to the core (no postcornual region is preserved). There are no distinguishable sutures, keeling, or transverse ridges. Unfortunately, the preservation of the core does not allow for confident evaluation of core hollowing or the presence/absence of cranial sinuses. The specimen is mediolaterally flattened and the angle between the pedicle and frontal bone does not suggest significant lateral divergence.

Discussion. Although the DNM 143 horn core is fragmentary, the apparent mediolaterally-flattened morphology and minimal lateral divergence (combined with the absence of keeling and transverse ridges) is consistent with the specimen representing Hippotragus (Gentry, 2010). Although hippotragins have not been previously described from Drimolen, the tribe and/or genus Hippotragus is frequently recovered in karstic deposits in the region (Vrba, 1973; Brain, 1981).

Family SUIDAE Gray, 1821

Subfamily SUINAE Gray, 1821

Tribe PHACOCHOERINI Gray, 1868

Genus METRIDIOCHOERUS Hopwood, 1926

Type species. Metridiochoerus andrewsi Hopwood, 1926.

Metridiochoerus sp. Figure 7

Referred material. DNM 57, right maxillary third premolar. 


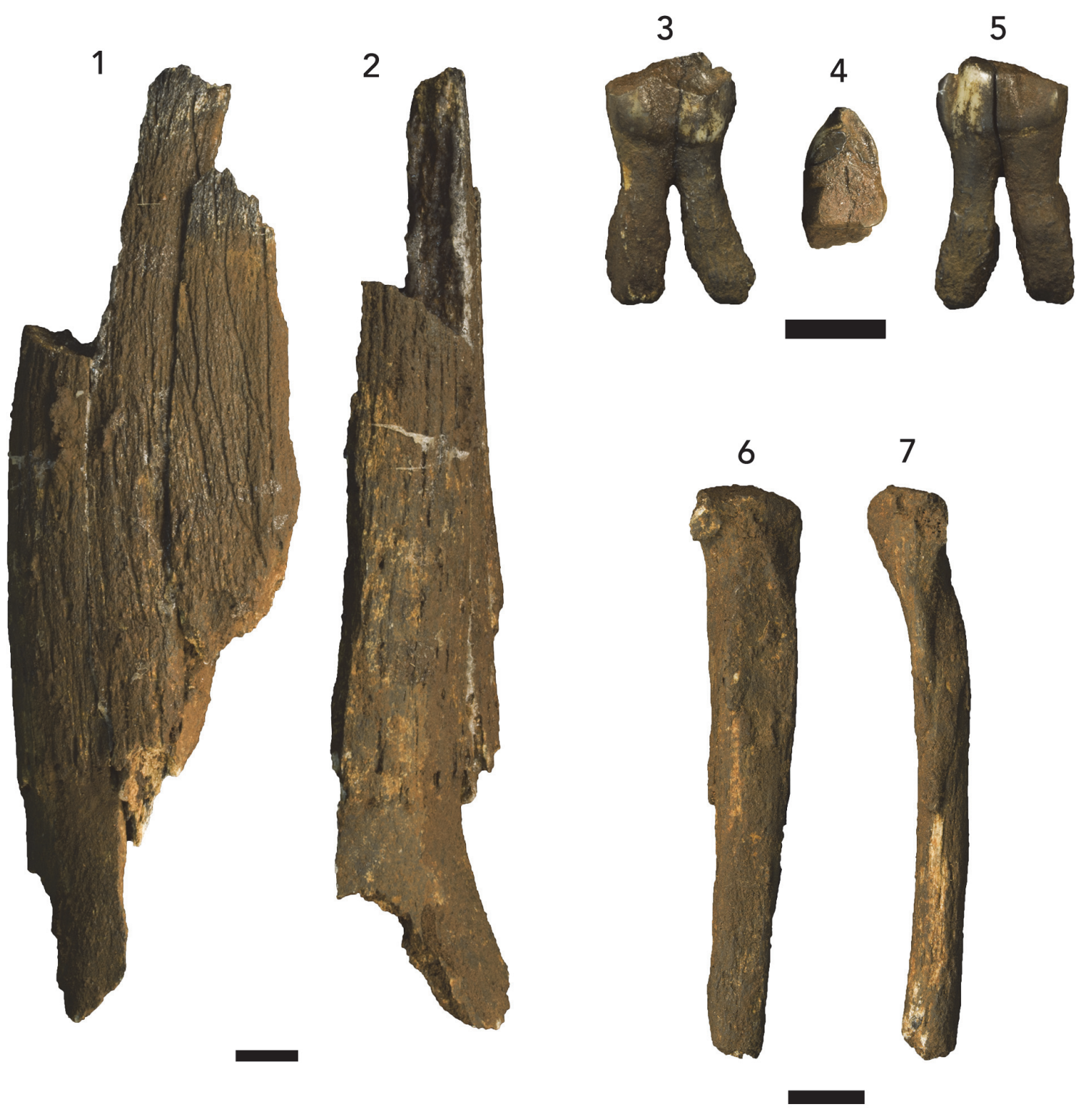

FIGURE 7. Artiodactyla and Perissodactyla from the Drimolen Makondo assemblage. 1 and 2, DNM 143-1, Hippotragus sp. partial horn core; 1, lateral and 2, anterior views. 3-5, DNM 57, Metridiochoerus sp. right maxillary third premolar; 3, lingual, 4, occlusal, and 5, buccal views. 6 and 7, cf. Eurygnathohippus cornelianus left proximal fourth metatarsal; 6, medial and 7, posterior views. Scale bars equal $1 \mathrm{~cm}$.

Description. The DNM 57 premolar is an isolated complete crown with light occlusal wear and complete roots (Figure 7.3-5). The tooth was refit from two separated pieces (mesial and distal halves) but the buccal contact surface displays no gap, and there is no apparent metric distortion. While occlusal wear has merged cusp elements (particularly distally), the crown displays a well-developed anterior cingulum and prominent paracone and metacone that are united through wear into an ectoloph. The small protocone is fused to the hypo- cone by a crest; the hypocone is similarly fused to the metacone through wear (likely representing an obliterated posterior cingulum).

Discussion. The morphological features of the DNM 57 crown align the specimen with early Metridiochoerus (alt. Potamochoeroides Dale, 1948; sensu Pickford, 2013) maxillary third premolar specimens. The Makondo specimen is directly comparable to the maxillary $\mathrm{P}^{3}$ morphology of Metridiochoerus andrewsi (Stage I; sensu Harris and White, 1979) from Makapansgat Member 3 (e.g., 
M331, M353, M1780, M1957, M2000, M2007, and M8x51). The DNM P3 (mesiodistal: $13.14 \mathrm{~mm}$; buccolingual: $9.11 \mathrm{~mm}$ ) is also within the range (or single standard deviation) of Makapansgat Member 3 $\mathrm{P}^{3}$ specimens in both mesiodistal $(12.20 \mathrm{~mm} ; \mathrm{n}=$ 6; s.d. 0.87 ; $\min .: 11.04$, max.: 13.53) and buccolingual $(9.88 \mathrm{~mm} ; \mathrm{n}=7$; s.d. 0.56 ; $\min .: 9.29 \mathrm{~mm}$, max.: $10.92 \mathrm{~mm}$ ) dimensions. Unfortunately, there are no maxillary third premolars recorded from early Pleistocene localities in the Cradle with later occurring South African Metridiochoerus andrewsi (e.g., Sterkfontein, Kromdraai, Swartkrans, Gondolin) to allow for comparisons of the Makondo specimen, either through lack of deposition/recovery/ identification, or the shedding of the anterior dentition in these later suids within the lineage.

Order PERISSODACTYLA Owen, 1848

Family EQUIDAE Gray, 1821

Tribe HIPPARIONINI Quinn, 1955

Genus EURYGNATHOHIPPUS van Hoepen, 1930

Type species. Eurygnathohippus cornelianus van Hoepen, 1930.

\section{cf. Eurygnathohippus cornelianus van Hoepen, 1930}

Figure 7

Referred material. DNM 13, left proximal fourth metacarpal.

Description. The DNM 13 partial left fourth metacarpal preserves a robust proximal epiphysis and a portion of a gradually narrowing diaphysis (Figure 7.6-7). Proximally, the epiphysis flares laterally, with a D-shaped articular surface that is bisected mediolaterally by a slight ridge dividing the surface into two subtriangular facets. The proximal diaphysis is nearly triangular in cross section, with marked rugose faceting on the medial aspect for the third metacarpal. At the point of breakage, the distal end of the diaphysis is still relatively robust and ovoid in cross section.

Discussion. There is a paucity of hipparionin postcrania in the South African fossil record, which makes direct comparison difficult. However, although not representing the equivalent element, the DNM 13 fourth metacarpal is appropriately sized for articulation with the G 2636 right third metacarpal, and similarly sized to the Gondolin GD 2 second and fourth metapodials (G 3309, G 6549) as well as the SKX 6778 second metatarsal (Churcher and Watson, 1993; Adams and Conroy, 2005; Adams, 2006).

Currently DNM 13 is the sole identifiable perissodactyl element from the Makondo deposits and the only equid described from the Drimolen site (Keyser et al., 2000). Although hipparionins are rarely recovered from South African terminal Pliocene and early Pleistocene deposits, craniodental and postcranial remains have been recovered from Cornelia-Uitzoek, Makapansgat Member 3, Kromdraai A, Swartkrans Members 13, and Gondolin GD 2 (Churcher, 1970; Reed, 1996; Churcher and Watson, 1993; Adams, 2006; Bernor et al., 2010; Brink et al., 2012). Currently the only genus and species of hipparion equid established from craniodental remains within contemporary Plio-Pleistocene deposits of South Africa is Eurygnathohippus cornelianus (and lineage; Bernor et al., 2010). Although the recovered element is not generically or specifically identifiable per se, this is the most likely attribution for the specimen given the currently understood hipparionin biogeography.

\section{DISCUSSION AND CONCLUSIONS}

The Drimolen Makondo faunal assemblage described here is interestingly devoid of several taxonomic groups common in the Drimolen Main Quarry deposits (Keyser et al., 2000; O'Regan and Menter, 2009). The absence of identifiable hominin specimens is noteworthy, particularly given that the Drimolen Main Quarry is one of the richest hominin-bearing dolomitic cave deposits in the Cradle of Humankind (Keyser et al., 2000; Lockwood et al., 2007; Moggi-Cecchi et al., 2010; Gallagher and Menter, 2011). This difference of the sampled Makondo faunas from the 'typical' Main Quarry faunas is mirrored by the lack of identifiable baboons (Papio), although some of the larger indeterminate cercopithecoid postcrania may represent either a papionin or the large bodied C. williamsi.

Carnivores are well-represented in the Drimolen Main Quarry, particularly the Felidae (O'Regan and Menter, 2009). The described Makondo sample may suggest a less diverse carnivore assemblage; however, Carnivora remains still account for $12.9 \%$ of all identifiable specimens recovered, a relatively high value in comparison with other karstic assemblages (Brain, 1981; Adams, 2006). Of particular note is the presence of all three largebodied families (Felidae, Hyaenidae, and Canidae) present in southern Africa during the terminal Pliocene and early Pleistocene, although the single identifiable canid from both deposits is the $\sim 3 \mathrm{~kg}$ Vulpes chama which is rare, as are most smaller canids in assemblages during this time period (Brain, 1981; Hartstone-Rose et al., 2013). We also highlight that both of the Makondo Dinofelis specimens vary metrically and/or morphologically from 
the previously described Main Quarry $D$. aff. piveteaui elements (O'Regan and Menter, 2009). The difference between Dinofelis remains at the two deposits suggests that either more than one Dinofelis species occurred in the region during the formation of the Drimolen Main Quarry and Makondo deposits and/or these deposits formed during two different time periods, which seems the more likely case given our current knowledge of the two deposits. The Makondo also seems unique compared to the Main Quarry in respect to the mineralization and preservation of the fossil material, the apparent occurrence of a greater percentage of carnivore taphonomy on the material, and the large numbers of articulated elements recovered. While this could represent different processes occurring in different parts of the same cavern, perhaps around different entrances, it may also be due to temporal variation.

Establishing the chronology of the Makondo deposits is ongoing, but the recovery of the single Metridiochoerus maxillary third premolar (with affinities to the Makapansgat Member 3 specimens at 3.0-2.6 Ma; Herries et al., 2013) may provide some initial evidence for the sampled Makondo faunas predating the Main Quarry assemblage. Unfortunately, at present there is a distinct lack of identifiable remains attributable to biochronologically sensitive species. While hipparionins are more typical of Pliocene faunal assemblages, three-toed horses do persist in South Africa to middle Pleistocene sites like Cornelia-Uitzoek ( 1.07$0.99 \mathrm{Ma}$; Brink et al., 2012), and the absence of Equus in the Makondo sample may simply reflect the size of the sample rather than deposit chronology.

The current bovid sample, despite comprising $78 \%$ of the identifiable faunal material, is also of limited value for assisting in biochronology or guiding palaeoecological interpretation given the paucity of identifiable craniodental remains (compared to the less diagnostic postcranial elements). The recovery of alcelaphin and antilopin remains in the Makondo is expected given the typical composition of late Pliocene and Pleistocene South African assemblages; both are present in the Main Quarry deposits, although the identification of a hippotragin is novel for Drimolen (Keyser et al., 2000). The Makondo bovid postcranial elements represent skeletally immature, large-bodied bovid (Class III sensu Brain, 1974) remains that may derive from a partially complete skeleton of a single individual that was interred in the deposits. While it is tempting to draw some taphonomic conclusion of the
Makondo representing a carnivore accumulation from the high percentage of carnivore remains and the occurrence of large, immature bovid skeleton prey specimens, establishing the full depositional history of the assemblage will require data from further excavation and faunal analysis.

\section{ACKNOWLEDGEMENTS}

The authors wish to thank two anonymous reviewers for their thoughtful critiques and comments regarding the article. We would also like to thank S. Potze and L. Kgasi (DNMNH), S. Badenhorst (DNMNH), L. Abraczinskas (Michigan State University), and B. Zipfel (University of the Witwatersrand) for facilitating access to the modern and fossil comparative specimens. Funding for excavation and analysis of the Makondo faunas was provided by an Australian Research Council Future Fellowship FT120100399 (to AIRH), the Australian Geoarchaeological and Palaeoanthropological Field School at Drimolen run by La Trobe University (AIRH) and the University of Johannesburg (CGM), the Department of Anatomy and Developmental Biology of Monash University (DSR, JWA) and National Research Foundation (NRF) grant to the University of Johannesburg (CGM). Permits to excavate at Drimolen (held by CGM and SEB) were granted by the South African Heritage Resource Agency. We would also like to thank D. and J. Smith, on whose property Drimolen is situated for permission to conduct the excavation and for their gracious assistance. Further, we would like to acknowledge the students of the 2014 La TrobeUJ field school for their help with the excavation. We also thank S. Baker, S. Mtshali, and C. Nieuwoudt for their help in the Drimolen lab and to $S$. Mokobane for his continued help with the Drimolen excavation.

\section{REFERENCES}

Adams, J.W. 2006. Taphonomy and paleoecology of the Gondolin Plio-Pleistocene cave site, South Africa. Ph.D. dissertation, Washington University in St. Louis, St. Louis, Missouri.

Adams, J.W. 2012. A revised listing of fossil mammals from the Haasgat cave system ex situ deposits (HGD), South Africa. Palaeontologica Electronica, 15:1-88.

Adams, J.W. and Conroy, G.C. 2005. Plio-Pleistocene faunal remains from the Gondolin GD 2 in situ assemblage, Northwest Province, South Africa, p. 243-261 In Lieberman, D.E., Smith, R.J., and Kelley, J. (eds.), Interpreting the Past: Essays on Human, Primate and Mammal Evolution in Honor of David Pil- 
beam. Brill Academic Publishers Inc., Boston, Massachusetts.

Anderson, M., Frost, S.R., Gilbert, C.C., and Delson, E. 2014. A reassessment of dental variation in the genus Cercopithecoides and its implications for species diversity. American Journal of Physical Anthropology, 153:67.

Backwell, L. and d'Errico, F. 2008. Early hominid bone tools from Drimolen, South Africa. Journal of Archaeological Science, 35:2880-2894.

Batsch, A.J.G.K. 1788. Versuch einer Anleitung zur Kenniss und Gesichte der Thiere und Mineralien. Erster Theil. Jena, Akademische Buchhandlung.

Bernor, R., Armour-Chelu, M., Gilbert, H., Kaiser, T., and Schulz, E. 2010. Equidae, p. 685-721. In Werdelin, L. and Sanders, W.J. (eds.), Cenozoic Mammals of Africa. University of California Press, Berkeley, California.

Berta, A. 1981. The Plio-Pleistocene hyaena Chasmaporthetes ossifragus from Florida. Journal of Vertebrate Paleontology, 1:341-356.

Blyth, E. 1875. Catalogue of mammals and birds of Burma. Journal of the Asiatic Society of Bengal, S. Austin and Sons, Hertford.

Bowditch, T.E. 1821. An analysis of the natural classification of Mammalia for the use of students and travelers. J. Smith, Paris.

Brain, C.K. 1974. Some suggested procedures in the analysis of bone accumulations from southern African Quaternary sites. Annals of the Transvaal Museum, 29(1):1-8.

Brain, C.K. 1981. The Hunters or the Hunted? University of Chicago Press, Chicago, Illinois.

Brink, J.S., Herries, A.I.R., Moggi-Cecchi, J., Gowlett, J.A.J., Bousman, C.B., Hancox, J.P., Grün, R., Eisenmann, V., Adams, J.W., and Rossouw, L. 2012. First hominine remains from a $\sim 1.0$ million year old bone bed at Cornelia-Uitzoek, Free State Province, South Africa. Journal of Human Evolution, 63:527-535.

Broom, R. 1937. LIX.-Notice of a few more new fossil mammals from the caves of the Transvaal. Journal of Natural History, 20(119):509-514.

Broom, R. 1948. Some South African Pliocene and Pleistocene mammals. Annals of the Transvaal Museum, 21(1):1-38.

Broom, R., Robinson, J.T., and Schepers, G.W.H. 1950. Sterkfontein ape-man Plesianthropus. Transvaal Museum Memoir No. 4. Transvaal Museum, Pretoria.

Chopra, S.R.K. 1957. The cranial suture closure in monkeys. Proceedings of the Zoological Society of London, 128:67-112.

Churcher, C.S. 1970. The fossil Equidae from the Krugersdorp caves. Annals of the Transvaal Museum, 26(6):145-168.

Churcher, C.S. and Watson, V. 1993. Additional fossil Equidae from Swartkrans, p. 137-150. In Brain, C.K. (ed.), Swartkrans A Cave's Chronicle of Early Man. Transvaal Museum Monograph No. 8, Transvaal Museum, Pretoria, 2nd edition.
Dale, M.M. 1948. New fossil Suidae from the Limeworks Quarry, Makapansgat, Potgietersrust. South African Journal of Science, 2:114-116.

de Rochebrune, A. 1883. Faune de la Sénégambie. O. Doin, Paris.

de Ruiter, D., Pickering, R., Steininger, C., Kramers, J., Hancox, P., Churchill, S., Berger, L., and Backwell, L. 2009. New Australopithecus robustus fossils and associated $\mathrm{U}-\mathrm{Pb}$ dates from Cooper's Cave (Gauteng, South Africa). Journal of Human Evolution, 56:497-513.

Delson, E. 1984. Cercopithecid biochronology of the African Plio-Pleistocene: correlation among eastern and southern hominid bearing localities. Courier Forschungsinstitut Senckenberg, 69:199-218.

Ewer, R.F. 1955. The fossil carnivores of the Transvaal caves. The Lycyaenas of Sterkfontein and Swartkrans, together with some general considerations of the Transvaal fossil Hyaenids. Proceedings of the Zoologic Society of London, 124(4):839-857.

Ewer, R.F. 1956. The fossil carnivores of the Transvaal caves: Canidae. Proceedings of the Zoological Society of London, 26(1):97-120.

Freedman, L. 1957. The fossil Cercopithecoidea of South Africa. Annals of the Transvaal Museum, 23:121-262.

Freedman, L. and Brain, C.K. 1972. Fossil cercopithecoid remains from the Kromdraai australopithecine site (Mammalia: Primates). Annals of the Transvaal Museum, 28:1-16.

Frisch, J. 1775. Das Natursystem der Vierfüssigen Thiere. C.F. Günther, Glogau.

Gallagher, A. and Menter, C.G. 2011. DNH 109: a fragmentary hominin near-proximal ulna from Drimolen, South Africa. South African Journal of Science, 107(5/6):1-4.

Gentry, A.W. 2010. Bovidae, p. 741-796. In Werdelin, L. and Sanders, W.J. (eds.), Cenozoic Mammals of Africa. University of California Press, Berkeley, California.

Geoffroy Saint-Hilaire, É. 1803. Catalogue des Mammifères du Museum National d'histoire naturelle. Muséum national d'histoire naturelle, Paris.

Gray, J.E. 1821. A natural arrangement of vertebrose animals. The London Medical Repository Monthly Journal and Review, 15:296-310.

Gray, J.E. 1868. Synopsis of the species of pigs (Suidae) in the British Museum. Proceedings of the Zoological Society of London, 1868:17-49.

Harris, J.M. and White, T.D. 1979. Evolution of the PlioPleistocene African Suidae. Transactions of the American Philosophical Society, 69(2):1-128.

Hartstone-Rose, A., Kuhn, B.F., Nalla, S., Werdelin, L., and Berger, L.R. 2013. A new species of fox from the Australopithecus sediba type locality, Malapa, South Africa. Transactions of the Royal Society of South Africa, 68(1):1-9. 
Havarti, K. 2000. Dental eruption sequence among colobine primates. American Journal of Physical Anthropology, 112:69-85.

Hay, O.P. 1921. Descriptions of species of Pleistocene Vertebrata, types or specimens most of which are preserved in the United States National Museum. Proceedings, United States National Museum, 59:599-642.

Hemprich, F.G. and Ehrenberg, C.G. 1832. Symbolae physicae, seu icones et descriptiones corporum naturalium novorum aut minus cognitorum quae ex itineribus per Libyam Aegyptium, Nubiam, Dongalam, Syriam, Arabiam et Habessiniam, pars zoologica II, anima. Officina Academica, Berlin.

Hendey, Q.B. 1974. The Late Cenozoic Carnivora of the Southwestern Cape Province, South Africa. Annals of the South African Museum, 63:1-369.

Hendey, Q.B. 1978. Late Tertiary Hyaenidae from Langebaanweg, South Africa, and their relevance to the phylogeny of the family. Annals of the South African Museum, 76:265-297.

Herries A.I.R. and Adams, J.W. 2013. Clarifying the context and dating of the Gondolin hominin tooth and the age range of Paranthropus in South Africa: a comment on Grine et al. 2012. Journal of Human Evolution, 65:676-681.

Herries, A.I.R., Pickering, R., Adams, J.W., Curnoe, D., Warr, G., Latham, A., and Shaw, J., 2013. A multi-disciplinary perspective on the age of Australopithecus in southern Africa, p. 21-40. In Leakey, R., Fleagle, J., and Reed, K. (eds.), The Paleobiology of Australopithecus. Vertebrate Paleobiology and Paleoanthropology Series, Springer Science and Business Media.

Hopwood, A. 1926. Some Mammalia from the Pliocene of Homa Mountain, Victoria Nyanza. Annals and Magazine of Natural History, 9:266-272.

Jablonski, N.G. and Frost, S. 2010. Cercopithecoidea, p. 393-428. In Werdelin, L. and Sanders, W.J. (eds.), Cenozoic Mammals of Africa. University of California Press, Berkeley, California.

Janis, C. 1988. An estimation of tooth volume and hypsodonty indicies in ungulate mammals, and the correlation of these factors with dietary preference, $p$. 367-387. In Russell, D., Santoro, J., and SigogneauRussell, D. (eds.), Teeth Revisited: Proceedings of the VIIth International Symposium on Dental Morphology. Memoirs of the Museum of Natural History (series C), Paris.

Jerdon, T.C. 1867. The mammals of India: a natural history of all the animals known to inhabit continental India. Thomas College Press, Roorkee.

Keyser, A.W. 2000. The Drimolen skull: the most complete australopithecine cranium and mandible to date. South African Journal of Science, 96:189-193.

Keyser, A.W., Menter, C.G., Moggi-Cecchi, J., Pickering, T.R., and Berger, L.R. 2000. Drimolen: a new hominid-bearing site in Gauteng, South Africa. South African Journal of Science, 96:193-197.
Lewis, M.E. 1995. Plio-Pleistocene carnivoran guilds: implications for hominin paleoecology. Ph.D. dissertation, Department of Anthropology, SUNY Stony Brook.

Linhart, J.B. 1968. Dentition and pelage in the juvenile red fox (Vulpes vulpes). Journal of Mammalogy, 49:526-528.

Linnaeus, C. 1758. Systema Naturae. Laurentii Salivii, Stockholm.

Lockwood, C.A., Menter, C.G., Moggi-Cecchi, J., and Keyser, A.W. 2007. Extended male growth in a fossil hominin species. Science, 318:1443-1446.

McKee, J.K., von Mayer, A., and Kuykendall, K.L. 2011. New species of Cercopithecoides from Haasgat, North West Province, South Africa. Journal of Human Evolution, 60:83-93.

Moggi-Cecchi, J., Menter, C., Boccone, S., and Keyser, A. 2010. Early hominin dental remains from the PlioPleistocene site of Drimolen, South Africa. Journal of Human Evolution, 58:374-405.

Mollet, O. 1947. Fossil mammals from the Makapan Valley, Potgietersrust. 1. Primates. South African Journal of Science, 43:295-303.

O'Regan, H.J. and Menter, C.G. 2009. Carnivora from the Plio-Pleistocene hominin site of Drimolen, Gauteng, South Africa. Geobios, 42:329-350.

Owen, R. 1848. Description of teeth and portions of jaws of two extinct Anthracotherioid quadrupeds (Hyopotamus vectianus and Hyop. bovinus) discovered by the Marchioness of Hastings in the Eocene deposits of the NW coast of the Isle of Wight: with an attempt to develop Cuvier's idea of the classification of pachyderms by the number of their toes. Quarterly Journal of the Geological Society of London, 4:103141.

Pickering, R., Kramers, J., Hancox, P., de Ruiter, D., and Woodhead, J. 2011. Contemporary flowstone development links early hominin bearing cave deposits in South Africa. Earth and Planetary Science Letters, 306:23-32.

Pickford, M. 2013. The diversity, age, biogeographic and phylogenetic relationships of Plio-Pleistocene suids from Kromdraai, South Africa. Annals of the Ditsong National Museum of Natural History, 3:11-32.

Quinn, J.H. 1955. Miocene Equidae of the Texas Gulf Coastal Plain. University of Texas at Austin, Bureau of Economic Geology.

Reed, K.E. 1996. The paleoecology of Makapansgat and other African Plio-Pleistocene hominid localities. Ph.D. dissertation, State University of New York, Stony Brook.

Smith, A. 1833. An epitome of African Zoology; or, a concise description of the objects of the animal kingdom inhabiting Africa, its islands and seas. South African Quarterly Journal, 2:89.

Sundevall, C.J. 1845. Öfversigt af däggdjursordningen Pecora. Öfversigt af Kongl. Vetenskaps-Akademiens Förhandlingar. Andra Årgången, 2(3):26-32. 
Swindler, D.R. 1976. Dentition of Living Primates. Academic Press, London.

Turner, A. 1993. New fossil carnivore remains from Swartkrans, p. 151-165. In Brain, C.K. (ed.), Swartkrans A Cave's Chronicle of Early Man. Transvaal Museum Monograph No. 8, Transvaal Museum, Pretoria. 2nd ed.

Tseng, J.Z., Li, Q., and Wang, X. 2013. A new cursorial hyena from Tibet, and analysis of biostratigraphy, paleozoogeography, and dental morphology of Chasmaporthetes (Mammalia, Carnivora. Journal of Vertebrate Paleontology, 33:1457-1471.

van Hoepen, E.C.N. 1930. Fossiele perde van Cornelia, O.V.S. Paleontologzese Navorsing van die Nasionale Museum, 2:1-24.

von den Driesch, A. 1976. A guide to the measurement of animal bones from archaeological sites: as devel- oped by the Institut für Palaeoanatomie, Domestikationsforschung und Geschichte der Tiermedizin of the University of Munich. Peabody Museum of Archaeology and Ethnology, Harvard University, Cambridge, Massachusetts.

Vrba, E.S. 1973. Two species of Antidorcas Sundevall at Swartkrans (Mammalia: Bovidae). Annals of the Transvaal Museum, 28:287-351.

Werdelin, L. and Lewis, M.E. 2001. A revision of the genus Dinofelis (Mammalia, Felidae). Zoological Journal of the Linnean Society, 132:147-258.

Werdelin, L. and Solounias, N. 1990. Studies of fossil hyaenids: the genus Adcrocuta and the interrelationships of some hyaenid taxa. Zoological Journal of the Linnean Society, 98:363-386.

Zdansky, O. 1924. Jungertiäre Carnivoren Chinas. Palaeontologia Sinica serie C, 2:1-149. 